Klaipeda University, Lithuania

ligita.simanskiene@gmail.com

Jurgita PAuŽUolienė

Klaipeda University, Lithuania

j.pauzuoliene@gmail.com
ARNAS STAŠKEVIČIUS

Klaipeda University, Lithuania

\title{
Changes IN SOCIETY DURING COVID-19 PANDEMIC: FROM THE POINT OF VIEW OF HEALTH CARE WORKERS
}

\begin{abstract}
Purpose: to define opinions on situation of health care workers during COVID-19 pandemic in Lithuania.

Methods: Analysis of research literature sources, systematization, synthesis, generalization, and comparison were applied it the theoretical level. Quantitative research i.e. questionnaire survey and data processing methods were applied in the empirical research. The collected empirical data was processed using SPSS (Statistical Package for the Social Sciences) program. During data processing, descriptive statistics were used -such as percentiles, mean, mode and standard deviation, ANOVA test.

Results: The results revealed that respondents were most afraid of the health of their family members. They also fear about the health of patients and feel anxious about the future in a general sense. Respondents tended to disagree that they feel dissatisfied that they cannot move freely and that they feel powerless to change anything. Respondents tended to disagree that there was a growing distrust of people, dissatisfaction with changes in life and that there was tension in the family. Assessing the opinion of respondents, what problems will become apparent after the spread of COVID-19, the results revealed that respondents most agree that the increase in financial problems; psychological problems and social will
\end{abstract}


increase. It is partially agreed that people will be afraid to leave the country and visit public places.

Discussion: Our research results did in Lithuania with health care workers actually shows the same results about problems arise with fear, anxiety and etc. at a personal level. We can conclude that the main problems that can occur during a pandemic are financial, social and psychological problems as were mentioned in another researcher's works. But we can add that health care workers agreed that situation is partly controlled in Lithuania, so not in all countries the same result.

KeYwords: Lithuania, Changes, Society, COVID-19, Health Care Workers

\section{INTRODUCTION}

The globalization process, which takes place in the world with all its advantages and disadvantages, determines sudden geopolitical, economical, technological and cultural changes, which inevitably affect the European Union and Lithuania as well. The globalization process has huge impact on national economies and how changes happen in a society. By understanding these changes scientists can do prognosis and governments can be prepared to deal with both changes happening at the moment and create models for the potential ones. How to react when an unexpected pandemic is coming? Change management is a multifaceted complicated process, and simply understanding the facts of change does not guarantee success. Governments need to be prepared for a fast pace global changes of any type - be it a technological breakthrough or a pandemic. Thus, the research problem is insufficient understanding of different aspects of changes in society during COVID-19 pandemic in Lithuania.

Purpose of research - to define opinions on situation of health care workers during COVID-19 pandemic in Lithuania. Used methods: analysis of research literature sources, systematization, synthesis, generalization, and comparison were applied it the theoretical level. Quantitative research i.e. questionnaire survey and data processing methods were applied in the empirical research.

Analysis of different impacts on societies during Covid-19. The term 'society' includes the human health aspect, but in everyday use, society has become a term that defines only the social wellbeing of humans. Socially 
sustainable communities are considered to be equitable, diverse, connected and democratic and provide a good quality of life. As such, none of these terms include the physical and mental wellbeing of humans. COVID-19 affects physical health most directly, but the impact on mental health also exists. Factors that affect mental health through COVID-19 include economic instability, domestic violence, substance use, derailment from regular schedule, and even insignificant things, like lack of sunlight. These have a great impact, but the above factors only consider the general population and not the toll on mental health for health care workers. Not only are healthcare workers in constant fear for their lives, they are also scared that they could potentially infect a family member they closely interact with. This takes a toll on their mentality that is unmeasurable in the current circumstances. Physical and mental health are closely related, and one taking a considerable hit will greatly impact the other (Hakovita M., Denuwara N 2020). Big group of researches (Lai and all, 2020) also were found that from 1257 respondents (health care workers) reported symptoms of depression, anxiety, insomnia, and distress, respectively. C.A. Harper, L.P. Satchell, D. Fido, D.Latzman (2020) also found that "fear" and anxiety have a functional role, and are related to increased compliance for improving public wellbeing. But authors recommend for other researches do not forget about real situation in the world, it is men context. While I.Zettler, C.Schild, L. Lillehot, L., R.Böhm (2020) are did their research on personal traits during Covid-19 and submitted the explanation why people have respond differently. Another interesting research did by B.Kuper-Smith, L. Doppelhofer, Y Oganian, G.Rosenblau, G., C.Korn (2020) about individuals beliefs to catch the infection. Authors found that individuals estimate the probability of getting infected with the virus, and of infecting others if infected themselves as lower for themselves than for someone similar to them.

COVID-19, apart from becoming the greatest threat to global public health of the century, is being considered as an indicator of inequity and deficiency of social advancement (Chakraborty I., Mait P., 2020). The COVID-19 outbreak affects all segments of the population and is particularly detrimental to members of those social groups in the most vulnerable situations, continues to affect populations, including people 
living in poverty situations, older persons, persons with disabilities, youth, and indigenous peoples (United Nations, 2020). It is states that the Covid-19 crisis has disrupted the normal practice of economy and governance, and scientific expertise also (A.Nelson, 2020). A.Androniceanu (2020) in his article mentioned that The European institutions are fighting the spread of coronavirus and providing assistance to the Member States that need equipment and support. Ozili P. and Arun T. (2020) analyzed the impact of social distancing policies on economic activities and stock market indices. The findings reveal that the increasing number of lockdown days, monetary policy decisions and international travel restrictions severely affected the level of economic activities and the closing, opening, lowest and highest stock price of major stock market indices. In contrast, the imposed restriction on internal movement and higher fiscal policy spending had a positive impact on the level of economic activities, although the increasing number of confirmed coronavirus cases did not have a significant effect on the level of economic activities. Authors B.Gavin, J.Hayden, D. Adamis, F.McNicholas (2020) in their paper compare psychological health of healthcare workers during Covid-19 and during SARS pandemic. In their opinion during current Covid-19 pandemic healthcare workers are exposed to unprecedented demands due to high mortality, rationing of Personal Protective Equipment and profound ethical dilemmas of rationing access to ventilators and other essential healthcare supplies. Such unexpected realities result in anxiety, stress, and even depression of some health care professionals. Zaka, A., E Shamloo, S., Fiorente, P., Tafuri, A. (2020) after analysis of rising psychological problems of health care workers during Covid-19 pandemic, summarized that both psychological systems and medical systems of health care require huge upgrades and need sufficient financial backing to be ready for future pandemics. They also found in their research that there is a need for systemic psychological support for health care workers. A.B.Al-Tammemi, A.Akour, L. Alfalah (2020) did research where they asked students about personal psychological problems during Covid-19. From 381 respondents most of respondents were regarded as having severe psychological distress $(n=265)$, followed by moderate psychological distress $(n=48)$, mild psychological distress $(n=41,10.8 \%)$, 
and no psychological distress $(\mathrm{n}=27)$. Results clearly show that Covid-19 has negative psychological impact not only on health care workers, but other citizens as well. N.Greenberg, M.Docherty, S.Gnanapragasam, S. Wessely (2020) pointed that should be support for health care workers from hospitals and government side. And some researchers found, that healthcare workers value an opportunity to reflect on the emotional impact of their work using Schwartz Rounds (Flanagan, Chadwick, Goodrich, Ford, Wickens, 2020). So it is mean that some organizations are trying to avoid psychological problems of health care workers.

E.Vaughan, T.Tinker (2009) wrote a very interesting paper where the focus of the analysis was communication within communities during pandemic. The main finding from their research was that message sent should be sensitive and relevant to the audience. Both state and local governments should have strategies and plans of communication with people which should involve trusted individuals from those communities. Paying attention to cultural and age differences is crucial. There are formulated recommendations how communicate with society: "telling people what is happening and why, explaining how long it will continue, providing meaningful activities for them to do while in quarantine, providing clear communication, ensuring basic supplies (such as food, water, and medical supplies) are available, and reinforcing the sense of altruism that people should, rightly, be feeling" (Brooks, Webster, Smith, Woodland, Wessely, Greenberg, Rubin, 2020, p. 919). Big authors team (Van Bavel and etc., 2020) presented different areas of interests during Covid-19. However loss of lives due to any pandemic causes definite irretrievable damage to the society (Chakraborty I., Mait P., 2020). We can state that during Covid-19 will be a lot of changes in society. Therefore S.Dubey, P.Biswas, R.Ghosh, S.Chatterjee, MJ.Dubey, S.Chatterjee, D.Lahiri, CJ.Lavie (2020) state that psychosocial crisis prevention and intervention models should be urgently developed by the government, health care personnel and other stakeholders. Also some research show that policy makers and mental health professionals working to prepare for potential disease outbreaks should be aware that the experience of being quarantined can, in some cases, lead to long-term adverse mental health consequences (Liu, Kakade, Fuller, Fan, Fang, Kong et al., 2012). 
We did the research to indicate, how health care workers feel after Covid-19 spread and to highlight the change which most affect people lives.

The methods of the research. Analysis of research literature sources, systematization, synthesis, generalization, and comparison were applied it the theoretical level. Quantitative research i.e. questionnaire survey and data processing methods were applied in the empirical research. In this survey 153 respondents from health care organizations participated: 74,5\% doctors, $24,2 \%$ nurses and 1,3 proc. medical attendants. The target group was respondents from hospitals. The research was done on May $1-10^{\text {th }}$ in Lithuania. The questionnaire consisted of six questions about respondent opinion how they felt during the spread of COVID19 infection; what is their approach to the problems that COVID-19 may cause in society. These questions are provided using a 5-score Likert scale (1 - completely agree, 5 - completely disagree). Three questions are designed to assess the demographic characteristics of the respondents.

Demographic characteristics of the respondents are provided in the table 1. Study participants consist of $17.6 \%$ men and 82.4 woman. In the below table you can see the distribution of study participants by age and work experience. Most subjects in the study are between ages 31 and 40 (45.8\% of participants). Also $41.8 \%$ of subjects had 6-15 years of work experience.

Tab. 1. Demograpfical data of respondents

\begin{tabular}{|c|c|c|c|}
\hline Age & Percent & Work experience & Percent \\
\hline $20-30$ & 15,7 & Till 5 year & 21,6 \\
\hline $31-40$ & 45,8 & $6-15$ years & 41,8 \\
\hline $41-50$ & 24,2 & $16-25$ years & 18,3 \\
\hline 51 and more & 14,4 & $26-35$ years & 14,4 \\
\hline & & $36-45$ years & 3,9 \\
\hline
\end{tabular}

Source: made by authors according 2020 research data. 
The collected empirical data was processed using SPSS (Statistical Package for the Social Sciences) program. During data processing, descriptive statistics were used -such as percentiles, mean, mode and standard deviation. The data was also processed by one-factorial dispersal analysis (ANOVA). To assess the reliability, or internal consistency, of a set of scale, Cronbach's alpha coefficient was used. The Cronbach's alpha coefficient value that for a properly and qualitatively composed questionnaire should be greater than 0,7 . In our case, the analysis of the questionnaire scale items obtained that Cronbach's alpha coefficient for all items varies from 0,7 to 0,9 . This shows that the scale is properly prepared (see table 2 ).

\section{Tab. 2. Questionnaire internal consistency}

\begin{tabular}{|c|c|c|c|}
\hline Questions & Cronbach's alpha & $\begin{array}{c}\text { Cronbach's Alpha } \\
\text { Based on Standard- } \\
\text { ized Items }\end{array}$ & $\begin{array}{c}\text { Number } \\
\text { of items }\end{array}$ \\
\hline $\begin{array}{c}\text { How do you feel after } \\
\text { Covid-19 spread in Lithuania? }\end{array}$ & 0,782 & 0,778 & 8 \\
\hline $\begin{array}{c}\text { How will Covid-19 change } \\
\text { most people lives in your } \\
\text { opinion? }\end{array}$ & 0,857 & 0,864 & 8 \\
\hline
\end{tabular}

Source: made by authors according 2020 research data.

\section{RESULTS OF THE RESEARCH}

The results revealed that the respondents were most afraid for the health of their family members (mean - 1.92, Mode -1 ). They also fear about the health of the patients and feel anxious about the future in a general sense (mean -2.50 , mode -2 ). Respondents tended to disagree that they feel dissatisfied that they cannot move freely (mean -2.71 , mode -2 ) and that they feel powerless to change anything (mean -2.8 , mode -2 ). Respondents tended to disagree that there was a growing distrust of people, dissatisfaction with changes in life and that there was tension in the family (for all statements in mode -4$)$. The performed ANOVA test revealed that the group of respondents aged 40-51 is the most dissatisfied that they cannot move freely. These results show that healthcare professionals do not feel powerless in this situation. 
Tab. 3. Results to the question "How do you feel after Covid-19 spread in Lithuania?"

\begin{tabular}{|c|c|c|c|}
\hline Statements & Mean & Mode & $\begin{array}{c}\text { Std. } \\
\text { Deviation }\end{array}$ \\
\hline I'm afraid for patients' health & 2,55 & 2 & 1,045 \\
\hline I feel anxious about the future in general & 2,50 & 2 & 1,209 \\
\hline $\begin{array}{c}\text { I feel dissatisfied that I can't move freely (travel, } \\
\text { visit public spaces, etc.) }\end{array}$ & 2,71 & 2 & 1,218 \\
\hline Distrust of people is growing & 3,08 & 4 & 1,197 \\
\hline I am afraid for the health of my relatives & 1,92 & 1 & 1,127 \\
\hline I am unhappy because I had to change my \\
lifestyle & 3,22 & 4 & 1,154 \\
\hline $\begin{array}{c}\text { I feel growing tension in my personal } \\
\text { relationships (family, etc.) }\end{array}$ & 3,84 & 4 & 1,138 \\
\hline I feel powerless to change anything & 2,88 & 2 & 1,210 \\
\hline
\end{tabular}

Source: made by authors according 2020 research data.

Assessing the opinion of the respondents, what problems will become apparent after the spread of COVID-19, the results revealed that most respondents agree that the increase in financial problems (mean - 1.50, mode -1 ); psychological problems (mean - 1.73, mode - 2) and social problems (mean - 1.94, mode - 2) will increase. It is partially agreed that people will be afraid to leave the country (mean -2.80 , mode -3 ) and visit public places (mean - 2.73, mode - 3). An ANOVA test with respondent age revealed that respondents with $36-45$ years of experience agree with the statement that dissatisfaction with immigrants will increase.

Results prove the fact that rises of societal problems is unavoidable. Some which already were very severe such as alcohol consumption or financial vulnerability and loneliness will experience a further increase.

80.4 percent of the respondents agreed that the situation is partly controlled in Lithuania, 16.3 percent of the respondents agreed that the situation is fully under control and 3.3 percent considers the situation to be completely out of control. 
Tab. 4. Results to the question "How will Covid-19 change most people lives in your opinion?"“

\begin{tabular}{|c|c|c|c|}
\hline Statements & Mean & Mode & $\begin{array}{l}\text { Std. } \\
\text { Deviation }\end{array}$ \\
\hline $\begin{array}{l}\text { Social problems will increase (eg alcohol } \\
\text { consumption) }\end{array}$ & 1,94 & 2 & ,898 \\
\hline Psychological problems will increase & 1,73 & 2 & ,795 \\
\hline Most people will feel isolated & 2,07 & 2 & 991 \\
\hline People will be afraid to visit public spaces & 2,73 & 3 & 1,106 \\
\hline People will be afraid to leave the country & 2,80 & 3 & 1,095 \\
\hline $\begin{array}{c}\text { There will be an increase of distrust towards } \\
\text { immigrants }\end{array}$ & 2,21 & 2 & ,964 \\
\hline $\begin{array}{l}\text { There will be an increase of domestic } \\
\text { violence }\end{array}$ & 2,14 & 2 & ,942 \\
\hline Financial problems will increase & 1,50 & 1 & 689 \\
\hline
\end{tabular}

Source: made by authors according 2020 research data.

Tab. 5. Results from respondent option if the government is controlling the situation after the spread of Covid-19?

\begin{tabular}{|c|c|c|}
\hline Statements & Frequency & Percent \\
\hline The situation is fully controlled & 25 & 16,3 \\
\hline The situation is partially controlled & 123 & 80,4 \\
\hline The situation is completely out of control & 5 & 3,3 \\
\hline Total & 153 & 100,0 \\
\hline
\end{tabular}

Source: made by authors according 2020 research data.

Governments are rightly focused on controlling the spread of the virus and saving lives. The measures required, on the advice of public health experts, are proving effective. At the same time, they are affecting people's jobs, livelihoods and standards of living, communities and families. Summarizing the results, it can be concluded that the health care workers are most concerned of the health of relatives and patients. The main problems that can occur during 
a pandemic are financial, social and psychological problems. These problems will lead to changes in societies around the globe.

\section{Conclusions}

The results revealed that the respondents were most afraid for the health of their family members. They also fear about the health of the patients and feel anxious about the future in a general sense. Respondents tended to disagree that they feel dissatisfied that they cannot move freely, that they feel powerless to change anything, that distrust of people is growing, dissatisfaction with changes in life and that there is tension in the family. The main problems which were indicated in our research are the growth of financial, social and psychological problems. And these problems are will have and already had biggest changes in society. Most of respondent state that the situation in Lithuania is partially controlled and only few respondents consider the situation to be completely out of control.

In general we can say that the pandemic has affected every aspect of life around the globe, from individual relationships to institutional operations to international collaborations it also affected everyone individually and caused a lot of changes in society.

\section{Bibliography}

Al-Tammemi, A.B., Akour, A., Alfalah, L. (2020). Is it Just About Physical Health? An Internet-Based Cross-Sectional Study Exploring the Psychological Impacts of COVID-19 Pandemic on University Students in Jordan Using Kessler Psychological Distress Scale. Research Squere. DOI:10.21203/RS.3.RS-29439/V1.

Androniceanu, A. (2020). Major structural changes in the EU policies due to the problems and risks caused by COVID-19. Administratie si Management Public, 34, 137-149. DOI: 10.24818/amp/2020.34-08.

Brooks,S.K., Webster,R.K. Smith,L.S. Woodland, L., Wessely,S., Greenberg, N., Rubin, G.J. (2020). The psychological impact of quarantine and how to reduce it: rapid review of the evidence, Lancet 2020; 395: 912-20 Published Online February 26, https://doi.org/10.1016/S0140-6736(20)30460-8. 
Chakraborty I., Maity P. (2020). COVID-19 outbreak: Migration, effects on society, global environment and prevention // Science of the Total Environment, p. 1-7. ISSN 0048-9697.

Dubey S, Biswas P, Ghosh R, Chatterjee S, Dubey MJ, Chatterjee S, Lahiri D, Lavie CJ (2020). Psychosocial impact of COVID-19, Diabetes \& Metabolic Syndrome: Clinical Research \& Reviews, doi: https://doi.org/10.1016/j.dsx.2020.05.035.

Flanagan E, Chadwick R, Goodrich J, Ford C, Wickens R. (2020). Reflection for all healthcare staff: a national evaluation of Schwartz rounds. J Interprof Care; 34:1402.10.1080/13561820.2019.163600831390225.

Gavin, B., Hayden, J., Adamis, D., McNicholas, F. (2020). Caring for the Psychological Well-Being of Healthcare Professionals in the Covid-19 Pandemic Crisis. Irish Medical Journal; Vol 113; No. 4; P51. ISSN 0332-3102.

Greenberg, N., Docherty, M., Gnanapragasam, S., Wessely, S. (2020). Managing mental health challenges faced by healthcare workers during covid-19 pandemic. BMJ 2020; 368:m1211 doi: 10.1136/bmj.m1211 (Published 26 March 2020).

Hakovita M., Denuwara N (2020). How COVID-19 Redefines the Concept of Sustainability // Sustainability 2020, 12, 3727, p. 1-4.

Harper, C.A., Satchell, L.P., Fido D., Latzman, D. (2020). Functional Fear Predicts Public Health Compliance in the COVID-19 Pandemic. International Journal of Mental Health and Addiction. Springer. https://doi.org/10.1007/s11469-020-00281-5

Kuper-Smith, B., Doppelhofer, L., Oganian, Y., Rosenblau, G., \& Korn, C. (2020). Optimistic beliefs about the personal impact of COVID-19. PsyArXiv Preprints. https://doi.org/10.31234/osf.io/epcyb.

Lai, J. and all. (2020). Mental Health Outcomes Among Health CareWorkers Exposed to COVID-19. JAMANetwork Open | Psychiatry. March 23. JAMA Network Open doi:10.1001/jamanetworkopen.2020.3976.

Liu X, Kakade M, Fuller CJ, Fan B, Fang Y, Kong J, et al.( 2012). Depression after exposure to stressful events: lessons learned from the severe acute respiratory syndrome epidemic. Compr Psychiatry. 53:15-23. ISSN 0010-440X.

Nelson A. (2020). Society after Pandemic. https://items.ssrc.org/covid-19-and-thesocial-sciences/society-after-pandemic/.

Ozili P., Arun T. (2020). Spillover of COVID-19: impact on the Global Economy // SSRN Electronic Journal, p. 1-27. ISSN 1556-5068.

United Nations (2020). Department of Economic and Social AffairsSocial Inclusion. The Social Impact of COVID-19. https://www.un.org/development/desa/ dspd/2020/04/social-impact-of-covid-19/. 
Van Bavel, J.J. and etc. (2020). Using social and behavioural science to support COVID-19 pandemic response. Perpective. Nature Human Behaviour. Springer Nature Limited. ISSN 2397-3374.SSN 0.10.

Vaughan, E., Tinker, T. 2009. Effective Health Risk Communication About Pandemic Influenza for Vulnerable Populations. American Journal of Public Health. Supplement 2, Vol. 99, No. S2. doi:10.2105/AJPH.2009.162537.

Zaka, A., E Shamloo, S., Fiorente, P., Tafuri, A. (2020). COVID-19 pandemic as a watershed moment: A call for systematic psychological health care for frontline medical staff. Journal of Health Psychology 1-5. Sage. ISSN 1359-1053.

Zettler, I., Schild, C., Lillehot, L., \& Böhm, R. (2020). Individual differences in accepting personal restrictions to fight the COVID-19 pandemic: results from a Danish adult sample. PsyArXiv Preprints. https://doi.org/10.31234/osf.io/pkm2a. 